\title{
Uniportal sleeve lobectomy for lung cancer
}

\author{
Dmitrii Sekhniaidze, Malik Agasiev, Tatyana Obuhova
}

Department of Thoracic Surgery, Regional Clinic Hospital, Tyumen, Russia

Correspondence to: Dmitrii Sekhniaidze, MD. Department of Thoracic Surgery, Regional Clinic Hospital, Tyumen, Russia. Email: skirrr@mail.ru.

\begin{abstract}
Over the last years video-assisted thoracic surgery (VATS) has become more popular as it has a number of advantages comparing to the classical thoracotomy (less postoperative pain, reduced blood loss, cosmetic effect, etc.) A short time ago it was generally thought that it was impossible to make certain surgeries (including bronchoplasty) through single port approach. However, improvement of manual skills, more advanced stapling devices, tools and surgical needles have made it possible to perform surgeries practically of any extent observing the oncological principles of operational intervention.
\end{abstract}

Keywords: Video-assisted thoracic surgery (VATS); uniportal; sleeve lobectomy; lung cancer

Received: 01 August 2017; Accepted: 17 August 2017; Published: 07 November 2017.

doi: 10.21037 /jovs.2017.08.17

View this article at: http://dx.doi.org/10.21037/jovs.2017.08.17

\section{Introduction}

Since the first reported video-assisted thoracic surgery (VATS) bronchial sleeve lobectomy was published (1), more and more technical challenges have become reality, even uniportal VATS bronchial sleeve lobectomy (2).

Our medical center makes different kinds of VATS resections, namely, lobectomy, sleeve and double sleeve lobectomy, sleeve carinal resection. In this article we share our experience on VATS sleeve lobectomies. The most frequently made procedure in this kind of surgeries in our clinic is the right upper sleeve lobectomy.

\section{Patient selection and workup}

We perform this kind of surgeries as an alternative to pneumonectomy for patients who have low functional reserves. Before the surgery patients undergo the compulsory examination of all the organs and systems to exclude contraindications and assess the degree of surgical intervention and possible risks.

\section{Pre-operative preparation}

Pre-operative preparation is the same as for the standard thoracotomy because of the high risk of conversion. Central venous line, arterial line and epidural catheter are placed.
All the necessary monitoring lines are also inserted. We use a double lumen endotracheal tube with general anesthesia. Patient is positioned in standard lateral decubitus.

\section{Equipment preference card}

We usually use a conventional instrument set, which includes a high definition $30^{\circ}$ camera, articulated staplers and forceps, vascular clips, endoscopic clamps, energy devices, an endoscopic needle holder, a long scalpel and a knot pusher.

\section{Procedure}

VATS sleeve-resection must be performed observing oncological principles, specifically, not less than $5 \mathrm{~mm}$ tumor-free margins of the bronchial stump confirmed by intraoperative frozen section; "en bloc" resection; the systematic lymphadenectomy performance.

The incision placement is a very important part. Usually we use a $4 \mathrm{~cm}$ long incision between anterior and middle axillary lines. However, the intercostal space depends on the surgery planned. On the left side the $5^{\text {th }}$ intercostal space is always used. For the right upper sleeve lobectomy the $4^{\text {th }}$ intercostal space is more convenient. For the right lower lobectomy we usually use the $5^{\text {th }}$ intercostal space (2).

After making an approach the pleural exploration must 


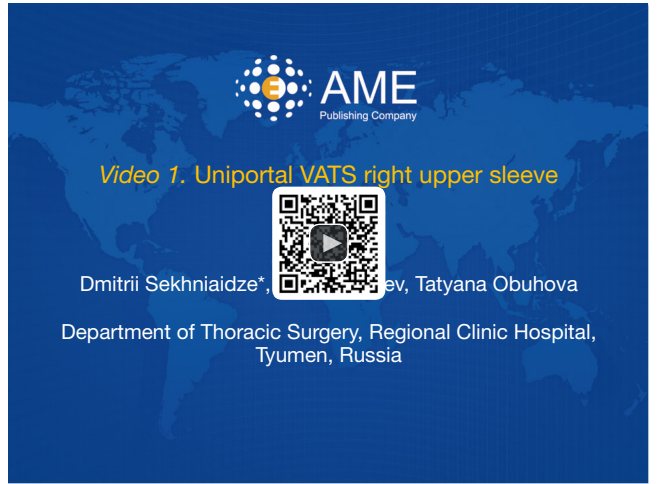

Figure 1 Uniportal VATS Right upper sleeve lobectomy (4). Available online: http://www.asvide.com/articles/1793

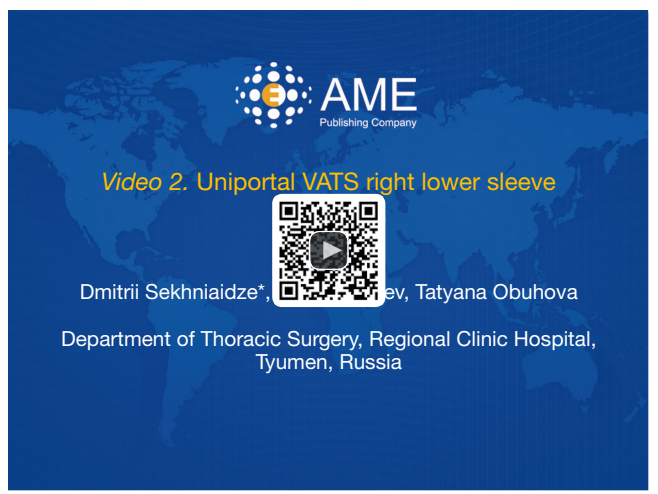

Figure 2 Uniportal VATS right lower sleeve lobectomy (5). Available online: http://www.asvide.com/articles/1794

be done. If there are no contraindications we start the surgery. The mediastinal pleura are usually opened with a hook or an energy device, the pulmonary ligament is divided to reach a better mobilization of the lung. Vessels are divided and transected by vascular staplers.

Next step is bronchi division. The lymphadenectomy must be accomplished before the bronchial resection. It helps mobilize bronchi, relieve manipulation and avoid tension on sutures.

Right after the completion of the lymphadenectomy we perform resection of the bronchus by a long scalpel and scissors. Surgical margins must be confirmed by intraoperative frozen section. If the surgical margin is positive-we resect it; if the surgical margin is free-we start to perform an anastomosis.

The principles of the VATS bronchoplasty are the same as for open surgery. The anastomosis must be performed free of tension for mucosa to mucosa approximation (3).
We normally make anastomosis by "V-lock" or "Prolene" adapting membranous and cartilaginous parts of the bronchi to be connected. After making anastomosis the water test is performed to check its air-tightness. After that a chest tube is placed.

\section{VATS right upper sleeve lobectomy}

The first step is section of pulmonary ligament. Then we divide upper lobe vessels and transect them by an endostapler. Sometimes we use only one stapler to transect the anterior trunk and the upper lobe vein. We usually clip the second segmentary artery with Hemolock or use metal clip and transect the artery using Harmonic or LigaSure. Next step is completion of the fissure by endostaplers. Then we perform the lymphadenectomy to relieve the division of the right main and intermedium bronchi. After completion of the division we resect them by a long scalpel and scissors. The surgical margins undergo a frozen section biopsy. If they are free we start making an end-to-end anastomosis. Usually we use a running suture by "V-lock" or "Prolene" (Figure 1) (4).

\section{VATS right lower sleeve lobectomy}

Dividing structures of the lower lobe does not differ from the standard open lower lobectomy. In the presented case we planned to perform the right lower lobectomy. The lower lobe vessels were divided and transected. After that the lymphadenectomy was performed. The lobar bronchus was transected by a long scalpel. The frozensection examination of the bronchial margins was positive. So we resected the intermediate and middle lobe bronchi and made anastomosis between them. The frozen-section examination of the resected bronchial margins was negative (Figure 2) (5).

\section{VATS left upper sleeve lobectomy}

The arterial and venous vessels to the left upper lobe are divided sequentially. Division of the anterior aspect of the fissure is completed in a similar manner to that on the right side. Next step is bronchi division which is accompanied by lymphadenectomy. Gentle dissection of the lymph nodes helps to relieve manipulations on bronchi. When the bronchi division is completed we estimate the prevalence of the malignant process and resect the left main and lobar bronchi by a long scalpel and scissors. The upper lobe is 


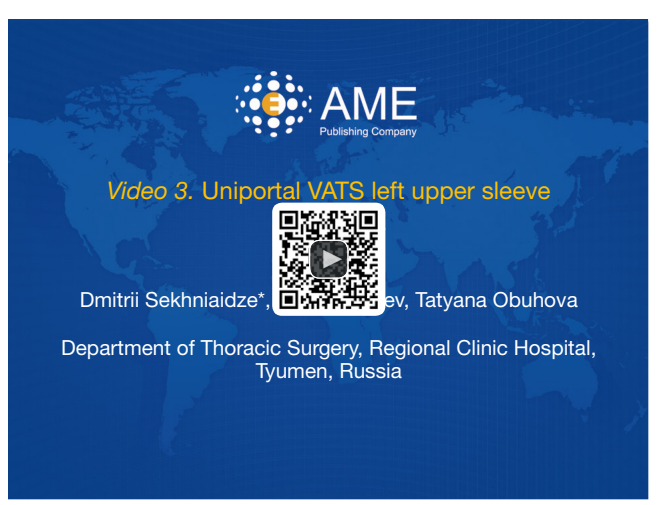

Figure 3 Uniportal VATS Left upper sleeve lobectomy (6). Available online: http://www.asvide.com/articles/1795

extracted from the pleural cavity in a bag. Then we make end-to-end anastomosis between the left main and lower lobe bronchi making uninterrupted suture (Prolene or V-lock). It is important to take particular care not to damage the pulmonary artery. Retraction of the PA using a mounted pledget may be helpful. When the anastomosis is performed we make a water test to check connection for leaks. Next we finish the lymphadenectomy. Finally, the inferior pulmonary ligament is divided up to the inferior vein level to facilitate expansion of the lower lobe (Figure 3) (6).

\section{VATS left lower sleeve lobectomy}

This technique is performed in the same way as the previous one. After the transection of the lower lobe vessels we expose the bronchi. Then we resect them and extract the lower lobe from the pleural cavity in a bag. Then endto-end anastomosis between the left main and upper lobe bronchi is performed. A water test to check the anastomosis is made. Next we finish the lymphadenectomy.

\section{Postoperative management}

The patient is extubated in the Intensive Care Unit for 2 hours after the surgery. After that X-ray control is performed. Post-operative care includes adequate pain

doi: 10.21037 /jovs.2017.08.17

Cite this article as: Sekhniaidze D, Agasiev M, Obuhova T. Uniportal sleeve lobectomy for lung cancer. J Vis Surg 2017;3:159. control, intensive pulmonary physiotherapy, preventive antibacterial therapy. Early mobilization is strongly recommended. Chest drainage is removed on post-operative day 2. In case of need vacuum aspiration is continued until air leaks stop. The patient follows the same diet he keeps to before the surgery. A pre-discharge fibrobronchoscopy is mandatory in our clinic to exclude the anastomotic dehiscence or bronco-pleural fistula. The patient is discharged on postoperative day 5-7.

\section{Acknowledgements}

None.

\section{Footnote}

Conflicts of Interest: The authors have no conflicts of interest to declare.

\section{References}

1. Santambrogio L, Cioffi U, De Simone M, et al. Videoassisted sleeve lobectomy for mucoepidermoid carcinoma of the left lower lobar bronchus: a case report. Chest 2002;121:635-6.

2. Gonzalez-Rivas D, Fernandez R, Fieira E, et al. Uniportal video-assisted thoracoscopic bronchial sleeve lobectomy:first report. J Thorac Cardiovasc Surg 2013;145:1676-7.

3. Gonzalez-Rivas D, Fieira E, Delgado M, et al. Uniportal video-assisted thoracoscopic sleeve lobectomy and other complex resections. J Thorac Dis 2014;6:S674-81.

4. Sekhniaidze D, Malik A, Obuhova T. Uniportal VATS Right upper sleeve lobectomy. Asvide 2017;4:476. Available online: http://www.asvide.com/articles/1793

5. Sekhniaidze D, Malik A, Obuhova T. Uniportal VATS right lower sleeve lobectomy. Asvide 2017;4:477. Available online: http://www.asvide.com/articles/1794

6. Sekhniaidze D, Malik A, Obuhova T. Uniportal VATS Left upper sleeve lobectomy. Asvide 2017;4:478. Available online: http://www.asvide.com/articles/1795 